\title{
A Social-Justice Informed Evaluation of a Mentorship-Based Program Pairing At-Risk Youth and Holocaust Survivors
}

\author{
Melissa L. Morgan-Consoli \\ Brian J. Stevenson \\ Erika Noriega Pigg \\ Wendy Eichler Morrison \\ Kelley Hershman \\ Carlos Roman \\ University of California Santa Barbara
}

\begin{abstract}
This paper describes a social justice informed, formative evaluation of a community-based intervention program in our community that paired marginalized Latinx youth and Holocaust survivor mentors. This program is a unique effort to address the issues facing this youth population through difficult dialogues and mentorship from a group who has clearly suffered oppression. Using a qualitative, community-based approach, eight program participants were interviewed to explore the aspects of the program that were helpful or challenging among youth mentees and survivor mentors. We reflect on the success of mentorship interventions in promoting bridges of understanding between populations with different combinations of power and privilege. Emergent themes from the evaluation suggest that this community-based mentorship program led to several positive outcomes, including increased openness to diversity, increased empathy, and increased potential meaning-making for mentor survivors, as well as some challenges such as clearer program expectations and program planning issues. Using a lens of Positive Youth Development and social justice, we detail the lessons learned from this mentoring program for future counselors and psychologists interested in program development and evaluation. We also provide reflections on the formative program evaluation process for future community-based researchers and the personal impact of the experience on the students in training. Finally, we reflect on impact validity and the systems level transformative change that can be promoted through community-based programs such as this one.
\end{abstract}

Keywords: program evaluation; at-risk youth; Holocaust survivors; mentoring; communitybased research, social justice

Successful youth mentoring interventions benefit from the cultivation of meaningful, quality relational encounters between the mentor and mentee (Ahrens, DuBois, Lozano \& Richardson, 2011). Mentoring in general has been shown to have many positive outcomes such as enhancing youths' relationships with peers and parents (Dubois, Holloway, Valentine \& Cooper, 2002; Elledge, Cavell, Ogle, \& Newgent, 
2010; Keller \& Pryce, 2010) and helping increase academic performance (Rhodes, Reddy, \& Grossman, 2005).

Many mentoring programs have been framed within a Positive Youth Development (PYD) framework, which focuses on increasing youth potential (Herrera et al., 2007). Though much of the literature on interventions related to PYD shows the mentoring relationship as an important agent for promoting prosocial behavior among adolescents (Scales, 2003; Werner \& Smith, 1992), the literature on cross-cultural community mentoring between under-represented youth and mentors is less developed. The limited literature in this area tends to examine the benefits of cross-cultural mentoring relationships within an academic context. Additionally, while these studies stress the need for understanding between cultures and multicultural training for graduate students, an explicit social justice framework for such mentoring programs has been less explored.

A report by Wolfson (2011) brought initial attention to the unique reciprocal benefits resulting from this particular cross-cultural mentoring program. The program was developed as an innovative approach to addressing the social issues facing poor and marginalized youth in the community. Many youth were having trouble staying in school and were becoming involved in illegal activities in the community during their free time. At the same time, the Jewish Holocaust survivors residing in the county, who were also affiliated with the local Jewish federation, felt they had something to offer the youth. Being victims of extreme oppression and discrimination themselves, their stories were thought to be quite relevant to some of the challenges that the youth in the community were facing. Relationships between elder adults and vulnerable youth have been suggested as beneficial (Taylor \& Dryfoos, 1998). The unique idea of pairing these survivors as mentors with these at-risk youth was conceptualized and put into place by Wolfson and the local Jewish federation. The program entailed a series of encounters in which two ostensibly incongruent groups shared their life experiences, participated in meaningful discussions, and worked collaboratively on artistic creations expressing the teens' life stories. The program was entitled Mis Tres Caras (My Three Faces) by the youth, who felt that the name reflected the past, present, and future. Wolfson's report detailed the unexpected and mutually positive, initial benefits resulting from the program, including validation of feelings about personal adversity, understanding new ways of relating to trauma, and shifting perspectives towards perpetrators with regard to vengeance and forgiveness. However, this program was never formally evaluated.

The current study extends the work of Wolfson (2011) by conducting a formative evaluation of the existing Mis Tres Caras (MTC) program. This evaluation provided useful information about helpful as well as challenging components of conducting a social-justice informed mentorship-based intervention program, which will likely help others in developing similar types of programming. We discuss lessons learned so that it may inform other counselors, psychologists and educators who are interested in developing and evaluating such programming. As we found, such programs may raise general awareness among both groups about the other, create empathy, and be a step in promoting societal, attitudinal change through difficult discussions. Additionally, such evaluation opportunities may provide service learning training opportunities for students, which have been found valuable in developing a social justice oriented approach (Toporek \& Worthington, 2014).

\section{Context for Current Study}

As researchers who study Latinx issues, and conduct community-based research, we were invited by the community agency sponsoring MTC to consult on the existing program. We considered the ways in which this research opportunity would provide relevant and applied knowledge to the community as 
well as provide a service learning opportunity for students and researchers to work with underserved communities. More specifically, we considered ways to engage in work that tries to change unjust systemic conditions, while learning the skills necessary for doing so, as has been called for in social justice oriented training for psychologists (Caldwell \& Vera, 2010, Toporek \& Worthington, 2014; Vera \& Speight, 2003). Additionally, scholars have called for practice and research that seek to end unjust, systemic, social conditions such as poverty, oppression and discrimination, thus changing the status quo (Albee, 2000; Prilleltensky, 1989).

The program facilitated open communication, understanding, and support between two marginalized groups. Thus, through our evaluation we hoped to call attention to the societal dialogues that are necessary to promote intergroup harmony and understanding (Worthington \& Arévalo Avalos, 2017). Social justice evaluators have noted the importance of conceptualizing program evaluation as a tool for effecting social change (Cook, 2014; Mark \& Henry, 2004) with careful attention paid to contextualizing findings to avoid blaming marginalized people for negative outcomes (Thomas \& Madison, 2010), and we attempted to do this. Finally, we believed that this project could lead to practical support for the sponsoring community agency so that they may continue such work, as well as beneficial outcomes for both mentees and mentors. These social justice considerations shaped how we conceptualized our consultant role, as well as guided our research approach.

The goals for the project, which were collaboratively determined between the researchers and MTC program developers, included the following three primary elements: (1) an assessment of the program's implementation from the perspective of participants, (2) an identification of the areas of programmatic impact, and (3) a list of "lessons learned" that could be used to guide program development and improvement, specifically reflecting on the social justice framework of the program. The researchers were also interested in how these findings could inform not only this specific program, but others like it.

\section{Program Rationale}

The original MTC program was developed based on observations precipitated by a permanent exhibition at the Jewish community center portraying the life experiences of Holocaust survivors and refugees in the local community. In particular, Wolfson (2011) observed that at-risk youth, many of Latinx background, brought to the exhibition through the police, probation departments, and "alternative school" programs, appeared acutely responsive to the survivors' stories. With this perspective, she created and implemented the first MTC program, with the hope that at-risk youth might benefit from deeper engagement with Holocaust survivors. Wolfson viewed the formation of the MTC program as "an opportunity to utilize the dwindling resource of the survivors' stories to contribute to enhancing selfworth and decreasing behaviors for this at-risk population" $(2011$, p. 3).

\section{Description of Program}

The MTC program paired Holocaust survivors and at-risk youth of predominantly Latinx backgrounds together for a six to eight week program. The youth were recruited from community groups or programs that focus on working with at-risk adolescents, including alternative schools and gang prevention programs. The number of youth in each group varied from four to eight participants. Mentors were volunteers from the Jewish community center who were Holocaust survivors. Mentors were not paired specifically with each youth, however interactions between survivor volunteers and youth, within a group structure, caused mentorship relationships to develop organically and stimulated deeper discussions around coping with discrimination, empathizing with marginalized others, and becoming an agent for social change. The program was created with the pragmatic aim of fostering positive outcomes 
(such as staying in school, not getting in trouble at school, avoiding law infractions) among youth participants as well as increased understanding and dialogue between marginalized and oppressed groups. The program took place in a county that has a bimodal distribution of SES and ethnicity, with White individuals (47.96\% of the population) making significantly more income (median household income $=\$ 66,000)$ than Latinx individuals $(42.9 \%$ of the population; median household income $=\$ 47,000)$ (Stanford Center on Longevity, 2011).

Program meetings took place once per week for one to two hours, and included survivor mentors, the youth, and a program facilitator from the community agency. Mentors presented their stories to the mentees, highlighting their Holocaust experiences in particular, and then were available to all mentees while the mentees engaged in various activities such as journaling, artwork, and crafts. Through these activities, Holocaust survivor mentors worked alongside the youth in the creation of their life stories. Participants also had discussions related to social issues including justice, discrimination, peer pressure, and bullying, which were facilitated by the project leader. Youth were asked to consider their reactions to the Holocaust survivor mentors' stories as well as their life narratives in their own artistic expressions. The program culminated with the presentation of the mentee projects to parents, mentors, and the community at a closing ceremony. Many mentors reported continued interaction with the youth after the formal programming had ended. For example, several mentors attended the high school graduations of the youth participants.

\section{Marginalized Youth and Program Participation}

Positive Youth Development (PYD), which focuses on the idea that coping strategies and life skills need to be developed during adolescence (Catalano, Hawkins, Berglund, Pollard \& Arthur. 2002), provides a valuable framework for youth prevention programming. The role of community has been found to influence PYD (Buhrmester, 1990; Scales, Benson, \& Mannes, 2006; Theokas et al., 2005). Specifically, supportive and positive peer relationships and close meaningful relationships with non-parental, adult mentors in the community have been significantly and positively associated with life satisfaction among adolescents (Oberle, Schonert-Reichl, \& Zumbo, 2011) as well as resilience and reduction of problem behaviors in adolescents (Allen, Kuperminc, Philliber, \& Herre, 1994). Community prevention programs and program staff and coordinators are therefore often facilitators in PYD. In multiple metanalytic studies, mentoring has been found to be significantly effective with at-risk youth; it has been related to a decrease in negative behaviors such as delinquency and substance use, and to an increase in educational attainment (DuBois et al., 2002; Gutman \& Schoon, 2015; Tolan, Henry, Schoeny, Lovegrove, \& Nichols, 2014).

One factor of mentoring that has been found to serve as positive stimulation is a cross-cultural mentoring relationship (Diversi \& Mechum, 2005). This aspect is particularly salient to the MTC program, given that the survivor mentors faced significant adversity during their experiences in the Holocaust and that the program engaged youth and mentors from different cultures and generations.

\section{Holocaust Survivors and Program Participation}

The original literature on Holocaust survivors focused on psychopathology and related variables. For example, studies focused on understanding trauma (e.g., Chodoff, 1963; Niederland, 1968) and predicting dysfunctional development within lifespan trajectory (e.g., Antonovsky, Maoz, Dowty \& Wijsenbeck, 1971). More recent studies have continued the emphasis on the trauma that these individuals experienced, branching out to include subsequent generations, such as in the study of vicarious trauma among survivors' children and grandchildren (Grodin, 2011; Kestenberg, 1998; Kline- 
Parker, 1988; Safford, 1995) and social policy (lecovich \& Carmel, 2010). In addition, a strengths-focused approach to research with Holocaust survivors has been utilized, taking into account factors such as resilience and positive mental health outcomes (Beiser \& Johnson, 1994; Hass, 1995; Higgins, 1994; Kline-Parker, 1988). However, there remains a dearth of literature on the impact of pro-social interventions for this unique geriatric group, such as participating in mentoring-based community programs. As people who have endured one of the most extreme forms of cultural oppression, the ways in which Holocaust survivors survived and were resilient may be potentially impactful for marginalized youth.

\section{Methods}

\section{Research Design}

A formative evaluation method was chosen as opposed to a summative one as the program had undergone some changes since its development. We wanted to capture an accurate picture of the current program so that results could be used for further development of the program (Rogers, 2002). The formative evaluation procedures were based on qualitative, community based research paradigms. Coming from the constructivist perspective of the existence of multiple truths (Ponterotto, Matthew, \& Raughley, 2013), semi-structured focus groups (youth participants) and semi-structured interviews (Holocaust survivor mentors) were used to explore mentor and mentee perspectives about their experiences in the program. True to community-based research paradigms, the participants as well as the researchers framed these explorations. Researchers did this by asking open-ended questions and then following participants' leads in the topics explored further. Additionally, research team members interviewed program leaders in order to gain insight regarding the structure, organization, and history of the program, as well as the goals for the program, before beginning the evaluation. In keeping with the recommendations for socially just qualitative research (see Lyons et al., 2013), the researchers strived to establish equity, access, participation, and harmony within all aspects of the qualitative procedures. For example, researchers provided their contact information for mentor participants to give further information or ask questions before or after the interviews, mentee participant focus groups were conducted within the regular meeting times and at regular meeting places for the particular groups, and all participants were asked for feedback on questions asked, with subsequent questions in the protocol being adapted to reflect their input.

\section{Researchers}

Consistent with qualitative paradigms that require researchers to make their assumptions explicit (Fassinger \& Morrow, 2013; Holloway \& Todres, 2003), the research team members discussed preconceived ideas and frameworks before beginning the evaluative study, as well as relevant personal variables that would likely influence the lens through which they interpreted results. All researchers had social justice foci as a part of their training; therefore, this was a significant lens through which the researchers all viewed the study. Also, all researchers entered the project with the belief that resilience can be fostered given the right systemic circumstances. With regard to relevant personal background, the first author is a counseling psychology faculty member and identifies as having mixed ethnicity (Mexican and European) and has no Judaism in her family background. While the first author has studied resilience, and worked with many Latinx immigrants and at-risk youth, she has not previously conducted research with Holocaust survivors. The second author was a counseling psychology doctoral student who identifies as a White male without any ties to Judaism. Prior to joining this project, this researcher had several years of experience providing counseling services to at-risk Latinx youth within a school setting. The third author identifies as Latina and comes from a low-income background. This researcher 
spent several years providing counseling and mentoring services to at-risk Latinx youth. This researcher does not have any strong religious affiliations, and has no ties to Jewish culture or religion. The fourth author identifies as Jewish and has family members who survived the Holocaust. This author began the research project valuing cross-cultural encounters. The fifth author identifies as Jewish American and grew up in an urban setting that was a predominately Latinx and Jewish community. The final author identifies as Latino and comes from a low-income background. This researcher does not have any ties to Judaism.

\section{Participants}

Participants were recruited via a purposeful sampling method, indicating that researchers were specifically interested in recruiting individuals who participated in the MTC program (both mentors and mentees) to gain their reactions and perspectives. The researchers recruited youth during the final MTC program sessions, where the study was described to the youth and they were invited to participate in focus group interviews. Out of approximately 11 invited participants, five youth participants, four males and one female, ranging in age from 15 to 18 , participated.

The MTC program director also connected researchers with Holocaust survivor mentors in order to gather further information regarding their experiences and perspectives on working within the MTC program. A total of three female survivor mentors (out of five mentors invited to participate) were interviewed individually. All survivor mentors had been involved with the MTC program for at least two years, had told their life stories to several groups of youth, and had been involved in programming activities throughout the program. All of the mentor participants who were interviewed had been involved with the same youth participants who were in the focus groups.

\section{Procedures}

Consenting and interested youth were invited to participate in a focus group with their peers from the program. Semi-structured interview protocols (see Appendix 1) were used. Each of the two focus groups was led by one to three researchers (one observing for training purposes in the case of three researchers) and lasted approximately one hour. In accordance with program evaluation goals, questions were asked about participants' experiences with the MTC program and any changes they had experienced during or after participation. Focus groups were conducted at the school or community organization from which the participants had been recruited for the MTC program. They were audiorecorded with participants' permission and transcribed verbatim by trained research team members.

Researchers conducted semi-structured, one-on-one interviews with three of the Holocaust survivor mentors. In accordance with our program evaluation goals, questions entailed general experiences with the MTC program, their relationships with the youth and any changes they felt had resulted from the program (see Appendix 2). Interviews lasted approximately one hour and were conducted at a private, comfortable location of the mentor's choice. These interviews were all audio-recorded with participants' permission and transcribed verbatim by trained research team members.

\section{Data Analysis}

Interview and focus group data was managed utilizing NVIVO qualitative software. Analysis was conducted using consensual qualitative research (CQR; Hill et al., 2005). We chose CQR because it has been identified as an approach which, like other qualitative methodologies, allows for rich descriptions in the language of the participants (Hill, Thompson, \& Williams, 1997); in this case, individuals who may otherwise not have their stories heard in society. 
Analysis was completed by two consecutive teams of three researchers. Prior to beginning the analysis of the interview transcripts, team members were required to read articles and attend a training on CQR. A coding scheme was created based on the analysis, which was an iterative process. The resultant coding scheme was adjusted until it ultimately represented all relevant data. An internal auditor, or person who was familiar with the topic of study and with CQR, was present to ensure that researchers developed domains (labels used to cluster similar data) and core ideas (summary of content for a specific case) that were indeed rooted and grounded in the data, and that analysis team members did not engage in "groupthink." Team members kept process notes to record how decisions were made during coding for future consistency. An outside auditor, an individual who was familiar with CQR but not intimately knowledgeable about the topic of research, provided team members with feedback, which was discussed and incorporated into the final coding scheme as deemed necessary by the researchers.

\section{Results}

Three domains emerged from the data through CQR analysis: (1) Program Impact, (2) Program Recommendations, and (3) Understanding of MTC Goal. Within each of these three domains youth and survivor views were delineated to highlight distinct perspectives. Each of these three domains were organized into categories, subcategories, and tertiary categories by the researchers to further explicate participants' responses. Emergent domains and categories are described below, along with exemplary responses for each, provided by the study participants. See Tables 1 and 2 for a visual overview of all domains, categories, subcategories, and tertiary categories.

\section{Program Impact - Youth's View}

From the youth focus groups, two categories emerged which described various changes that participants felt had occurred in their lives from having participated in MTC. These categories included: Changed Attitude About Others and Changed Attitude Within Self. Within both of these categories several subcategories emerged.

Changed attitude about others. Responses within this category were related to participants having increased positive consideration for other people. The two subcategories that emerged were Increased Empathy and Improved Relationships. Several responses were coded in the subcategory of Increased Empathy when respondents described the process of beginning to put themselves in the shoes of others. For example, one youth stated, "But the survivors here, when I heard the stories it hit me, you know...the thing that hit me the worst was when she cried at the end, it got me thinking...I would get emotional too if I was them." Another youth stated, "I think she cried at the end. She did. And I thought that was really nice, and it was just really touching. Although there wasn't a bond, I feel like I sort of know what she went through." Another youth participant described having changed attitudes about people who may be homeless by stating,

Usually I would just pass by those kinds of people. I remember one day that we were actually talking about this topic and we were saying that people are sometimes discriminated. Like if you're walking by someone and they look homeless or something, you kind of discriminate them, thinking that they're alcoholics and that's why they're on the street or drugs or another reason. But really, there is a story behind it, and it doesn't always have to be a negative one, if anything their whole family could have died, and they don't have anyone else to help them, so just a smile I guess can help them. 
In addition to increased empathy, some of the youth described having Increased Engagement in Relationships. Responses in this subcategory were similar in that they all described youth's new and/or improved connections with peers, family and/or community members. For example, one participant stated,

I learned from the Holocaust survivors... that they had to live separately from their parents at a young age and so they didn't get to be with their parents. And so now I have the opportunity to be with my parents, and I want to take advantage of that. So, that's why I spend a lot more time with my parents.

Relatedly, several of the youth's responses were coded within the subcategory of Increased Respect, which was defined as the teens demonstrating the value of other people through their positive actions. One youth described his feelings after participating in the program: "when we're walking and I see a person, mostly an older person, I want to be respectful...I'm just trying to be nicer to them."

Changed attitude within self. Responses in this category were all related to having a more positive view about one's life as a result of participating in the MTC program. Within this category, four subcategories emerged from the data: Betterment of Self, Feeling Empowered, Increased Gratitude, and Insight into Human Condition. The first of these subcategories, Betterment of Self, included responses that involved working toward improvement in some area of one's life. For example, one youth indicated that he is working on "not being in the streets that much any more and, like, focusing more in school." Another youth stated, "instead of proving to people that I'm not a negative person, that I'm not stupid, I'm proving to them that I could be somebody." Increased Gratitude, which is defined as reflecting on goodness of one's own life, included responses such as "I do appreciate my parents more...and I'm blessed to have everything I have and I feel like that's one thing the class made me realize throughout the whole thing, to just be blessed for what you have." Responses coded as Feeling Empowered were defined as the youth's recognized ability within self to influence change. For example, one youth stated, When people bully on other kids, a lot of people don't stand up for them...and after I went to MTC, I felt like, if I'm not the first one [to take a stand], no one is going to be the first one. I felt like this made me want to be the first one, so I can stop anything. It just takes one person and then everyone else goes too.

Lastly, several responses were coded as Insight into Human Condition, which is defined as the survivors' stories yielding an increase in the youths' awareness of the human role in atrocities. For example, one youth participant stated,

I actually like to share my knowledge, especially with my best friend. I'll go home and tell her, and be like 'I learned about the Holocaust' and she'll be like 'I already know about the Holocaust,' and I say 'you think you know about the Holocaust.' And I did too, but then I got here and it's such a different thing. Yeah in the books, it doesn't tell you why he did it... explained to her, and I was like this could happen again, this could happen to us.

\section{Program Impact - Survivor's View}

Based upon the perspectives of the Holocaust survivor mentors, three categories emerged pertaining to the positive outcomes of participating in MTC. These categories included: Developed Youth/Survivor Relationship, Gratifying Experience, and Increased Openness to Diversity. Several responses were coded as Developed Youth/Survivor Relationship to reflect a recurring theme of the survivor mentors' perceptions that a positive bond was formed with the youth participants. For example, one survivor participant stated, 
At first they were a little shy when we met and I spoke to them. But it became such a warm existence, that when we met at the [art studio], they all came and they hugged me and they embraced and it was really a wonderful experience.

All participants discussed having a Gratifying Experience of mentoring however, as exemplified by one survivor mentor's statement:

And yes, it has impacted me. Yes. And I felt that we have come through. And I could see the change in the kids when they opened up. And the way they were even... when they first started with the journal it was oh, what am I doing?...that's what's wonderful. And all of a sudden you see the influence, yeah and then they're working on it.

Another survivor mentor said, "Well part of it (the satisfaction), of course, you feel like giving back. And it is important that your stories are not forgotten. But that is the main reason: to give back."

Many responses were coded as Increased Openness to Diversity, which was defined as the survivor mentors reporting that their relationships with MTC youth changed their perceptions about marginalized youth. Some example quotes include, "what I found was so much empathy for these people and these young men, it was really unbelievable...it helps me in being even more tolerant than you think you are." Another participant stated,

I have a better understanding of the different ethnicities and different cultures, and it's bringing me closer to what happens when you come to a different country and you don't speak the language...in that sense, I felt more empathy for these kids.

\section{Program Recommendations - Youth's View}

Youth participants gave several recommendations concerning the aspects of the program that went well, as well as those that needed improvement. From this data, we determined the existence of both Helpful Program Components and Problematic Program Components.

Three subcategories emerged out of Helpful Program Components that were identified as improving program effectiveness: Group Format, Mentorship, and Projects. The Group Format category contained responses from youth participants who reported that they enjoyed the structure of meeting as a group. For example, one youth stated, "having a smaller group kind of made everything more like focused on every single student. I felt more, like, comfortable." The Mentorship subcategory was defined as the youth feeling supported by the adult volunteers and responses were coded into two separate tertiary categories: Personal Attention and Storytelling. The Personal Attention tertiary category included youth responses that were related to feeling that one-on-one attention from a mentor was particularly helpful. For example, one participant stated "she sat right next to me and started telling me about her story, looking me in the eyes. I guess that made me feel comfortable...just the way she told me her story." Within the Storytelling tertiary category, youth participants reported that the mentor providing personal narratives was helpful. One participant stated,

I was really curious to see and hear their stories and even though they were nothing like mine, I got to relate to them. Relate to them in a way l've never gotten to with someone before. Like to actually hear them, seeing them, and being there next to them was a lot different than what I read in a textbook.

Another youth stated, "even though they didn't know me, like the first day, they still opened up to me and told me their life story. So, I guess that was really important, for me. Well, it made me feel more 
comfortable." Finally, the Projects subcategory consisted of the youths' positive views on the use of creative activity projects (e.g., journaling or drawing). As an example, one youth stated, "I got the journal and started writing on it, and I was just like...I feel good you know, just like letting it out, like something that you don't want to tell nobody...I'm still writing to it."

Within the Problematic Program Components subcategory, two subcategories emerged from the data: Initial Program Atmosphere and Unmet Expectations. Responses coded in Initial Program Atmosphere described difficulty with the early environment of the program. For example, one youth stated,

I think something that would have helped would have been like group exercises to get comfortable with everyone at first, and then start talking about our lives. Not directly talking about our lives at first because like I said earlier, you don't want to open your life up to some stranger...I think they realized it was kind of a struggle to get the kids to talk about their lives.

The Unmet Expectations subcategory represented responses related to the youth feeling like the MTC program didn't meet the description of what participants were initially told to expect. For example, one youth stated,

Yea, I thought we were just going to be doing projects and like writing in journals and....you know when they explained it to me they said that it was going to be like art class or something like that and so... and so yea, that's what I was expecting I think I was just more expecting more like creativity and like art, art to it.

Another youth echoed similar feelings when he stated,

I thought it was going to be like more...more projects and stuff like they described it like oh this is going to be really fun you know like, you're going to do... you're gonna draw, you're gonna make stuff, like they're gonna show you a lot, they're gonna teach you a lot of new stuff that you guys didn't know before and then we just showed up... Like you're gonna do this project and stuff but like, naw, it was just like most of the lessons it was just lectures. But at the same time I got to admit...they taught me new things though, I didn't like know...It makes you think, you know?

\section{Program Recommendations - Survivor's View}

Survivor mentor participants identified many aspects of the MTC program that they perceived to be helpful or problematic. These responses were organized into two categories: Helpful Program Components and Problematic Program Components. There were several aspects of the MTC program that the survivor mentors found helpful, and these responses were organized into three subcategories: Creative Activities, Engaging Teens, and Unique Background of Survivors.

The Creative Activities subcategory contained mentor responses indicating that art and journaling activities were enjoyable and impactful for the youth as well as the survivors. For example, one mentor stated, "they were into the art, that sort of thing, and then it was great. It certainly seemed to have impacted them...I thought that was interesting because they expressed themselves through the art." Within the Engaging Teens subcategory, survivor mentors provided their views on effective methods for connecting with youth. For example, one survivor mentor stated, "I realized that I sort of had to go down to their level and see how they are and how they act, and then go according to that." Finally, the Unique Background of Survivors was a subcategory that contained responses reflecting that the cultural experiences of the mentors facilitated receptivity of teens. For example, one survivor mentor described, 
And I told them when I was their age nobody was allowed to play with me at school and they reacted to that and thought, you know, that shouldn't be that way and they didn't quite understand the depth of why, but they sympathized and I was very content with that moment.

Within the Problematic Program Components category, logistical and programmatic issues such as the following were discussed: frequent changes in MTC leadership, low numbers of youth enrolled in the MTC program, and transportation issues for youth to attend groups.

\section{Understanding of MTC Goal}

Both the youth and the survivor mentors offered their perceptions of the purpose of the MTC program. From these responses, there were often differing understandings of what the purpose of MTC was. For example, one youth stated, "I feel like they just taught us how to be more respectful...and not to judge people by how they look... and you should be happy for what you have." The survivor mentors offered several different understandings of MTC's purpose. For example, one survivor mentor stated,

To us, the biggest goal of the program is for them to be able to function in society; to be able to accept the fact that if somebody is going to be nasty to you, you don't reciprocate in the same manner.

Another survivor mentor responded, "I think the goal is partly that they understand what prejudice is and what it can lead to...." The third survivor mentor stated, "I think the goal is always for betterment; to improve whatever needs to be improved...to make them better people...education is always the goal."

Table 1

Coding Scheme of Youths' Responses

\begin{tabular}{|c|c|c|c|}
\hline Domain & Category & Subcategory & Tertiary Category \\
\hline \multirow[t]{6}{*}{ Program Impact } & $\begin{array}{l}\text { Changed attitude about } \\
\text { others }\end{array}$ & Increased respect & \\
\hline & & $\begin{array}{l}\text { Increased empathy } \\
\text { Increased engagement in } \\
\text { relationships }\end{array}$ & \\
\hline & $\begin{array}{l}\text { Changed attitude within } \\
\text { self }\end{array}$ & Feel empowered & \\
\hline & & Betterment of self & \\
\hline & & Increased gratitude & \\
\hline & & Insight into human condition & \\
\hline \multirow[t]{6}{*}{$\begin{array}{l}\text { Program } \\
\text { Recommendations }\end{array}$} & $\begin{array}{l}\text { Helpful program } \\
\text { components }\end{array}$ & Group format & \\
\hline & & Mentorship & Storytelling \\
\hline & & & Personal attention \\
\hline & & Projects & \\
\hline & $\begin{array}{l}\text { Problematic program } \\
\text { components }\end{array}$ & Initial program atmosphere & \\
\hline & & Unmet expectations & \\
\hline
\end{tabular}


Table 2

Coding Scheme of Survivors' Responses

\begin{tabular}{lll}
\hline \multicolumn{1}{c}{ Domain } & \multicolumn{1}{c}{ Category } & \multicolumn{1}{c}{ Subcategory } \\
\hline Program Impact & $\begin{array}{l}\text { Developed youth-survivor relationship } \\
\text { Increased openness to diversity }\end{array}$ & \\
\hline Program & & Creative activities were \\
Recommendations & Helpful program components & successful \\
& & Engaging teens \\
& Unique background of survivors \\
\hline Understanding of Understanding of MTC Goal & \\
\hline
\end{tabular}

\section{Discussion}

Results highlighted many points for discussion as well as "lessons learned" that are likely to be valuable to anyone interested in conducting programs focused on addressing social issues such as racism and prejudice and building bridges among marginalized communities. Specifically, the researchers noted a two-way learning process between the survivor mentors and youth, including the importance of empathy for both mentor and mentee, the impact of using history as a form of empowerment, and the use of other mediums as helpful in getting youth engaged in the programming.

Many gains for both youth and mentor survivors were in the area of new perspectives about the "other." For example, youth learned more about the Holocaust and Holocaust survivors. This new perspective went beyond seeing the survivors as just elderly citizens of a race and ethnicity different than their own. Similarly, the survivor mentors learned more about marginalized youth of today and the struggles that these youth face. Moreover, the youth participants indicated that, due to the facilitated dialogues in the program, they had increased empathy, respect, and engagement in relationships with others. This is particularly important given the power differentials and demographics of the participants and mentors: participants were primarily at-risk, sometimes low-income Latinx students, while mentors were European, middle class elders of society. Many of the youth were facing adversities such as poverty, discrimination and issues with gang membership. The Holocaust survivor mentors were able to relate stories of discrimination that they themselves had faced and thus build a connection of empathy between the mentors and mentees. Such a connection exemplifies the necessary components for societal understanding between groups and potential addressing of systemic issues such as racism and discrimination. The power differentials in some ways promoted even stronger realizations on the part of the youth, as many described in various ways that they had not previously realized how someone they had perceived as "other" could have had similar experiences to them.

Similarly, the survivor mentors also noted learning more and obtaining greater empathy concerning the lives of Latinx youth. In particular, they discussed ways in which the youth led more difficult lives than anticipated and how this led to an increased openness to diversity. Survivor mentors also reported overall satisfaction with or gratitude about their participation in the program, noting the ability to make a difference in the lives of the youth. More specifically, the mentors' in-depth learning about the lives of 
the youth promoted greater awareness of an unjust power structure that is the necessary foundational work for determining avenues for advocacy and social changes (Toporek \& Worthington, 2014). It also exemplifies that even when one has been a member of an oppressed group oneself, it is not always easy to recognize the adversities faced by other marginalized groups. Many mentors shared with us that they continued to be involved in the lives of the youth and volunteer for agencies that address societal injustices through social action as a result of their involvement in the program.

Another noteworthy aspect of the programming that seemed to stand out from other initiatives of this type was the use of historical context concerning power and oppression to empower participants in the present. As Holocaust survivor mentors educated youth on their experiences and lives, the youth seemed to realize parallels with their own lives and to feel that "if he/she could do it, so can I." This selfrealization and subsequent empowerment seemed to be one of the most effective aspects of this unique programming. Among the mentors, sharing their stories with a group of youth who face discrimination and marginalization also seemed to be quite meaningful, as mentors remembered and retold their stories in a way that interconnected the histories of both mentors and mentees, contributing to their common narrative and fostering broader reflection on systemic injustices.

The use of art projects and journaling were very popular with the youth participants and seemed to provide a non-threatening way for youth to explore their own histories and tell their own stories, which were often difficult. These findings are consistent with other literature that has highlighted the advantages of using artistic mediums of expression in dealing with adversities such as trauma and oppression (Eaton, Doherty, \& Widrick, 2007; Stuckey \& Noble, 2010). Through this supportive exploration experience, the art and journaling projects seem to be fostering a more positive self-image for the youth, which has been identified as a key ingredient of positive youth development (Lerner, Fisher, \& Weinberg, 2000) and also provided necessary reflection on difficult conversations about inequity and injustice, which led to greater awareness (Toporek \& Worthington, 2014). Survivor mentors seemed to model or inspire resilience and thriving as well as empathy.

There were several pragmatic lessons learned from the program implementation and evaluation. While we acknowledge that it is not likely such a program will be exactly replicated, lessons learned may be informative for any mentorship programming and/or program that works with marginalized populations. The first lesson learned pertained to the necessity for logistics such as transportation to events, timing of final events for participant and parent attendance, and consistency in programming. An issue of access, the need for attention to detail in these matters was paramount in ensuring the success of the program.

Secondly, it was very important to the youth that they be given an accurate idea of what they would be experiencing in signing up for the program, and that this be carried out as promised. Similarly, it is important that mentors be consistent in their understanding and communication of program goals to youth participants. Not having clear expectations of program goals was one of the main reasons for youth dissatisfaction in programming, and is reflected in the literature as a common difficulty (Spencer, 2007). This may be accomplished by involving the youth participants in the program creation and implementation, such as is called for in Community Based Participatory Research (CBPR) (Knightbridge, King, \& Rolfe, 2006). CBPR has been discussed as a research method for service learning that ensures that programs and interventions are relevant to community stakeholders/participants. Furthermore, it appears that the success of the intergenerational mentorship relationships in the MTC program was facilitated through storytelling, and the shared experiences of the survivor mentors. Counselors and 
psychologists interested in developing mentorship programs for marginalized youth that are focused on facilitating dialogue to increase understanding between groups would likely want to find mentors who are willing to share true, personal stories related to injustice and overcoming adversity with their mentees.

Finally, when developing mentorship programs for marginalized groups, it is important to consider integrating programming components that facilitate a sense of comfort and safety among youth for sharing their own personal stories. To that end, it is particularly important that adequate time be set aside at the start of any mentorship-based program for "getting to know you" or "ice breaker" activities, rather than diving straight into personal storytelling and self-disclosures. While the overall feeling ultimately seemed to be one of comfort on the part of the youth, initial difficulties were noted by both survivor mentors and mentees.

Outside of program specifics, we additionally reflected on the experiences of the student servicelearners who were conducting this analysis. We discussed that engaging in qualitative research and discussing the accounts provided by participants gave a rich foundation for engaging in our own difficult dialogues and systemic social justice considerations. For example, many of the analysis sessions resulted in long and detailed considerations of the lives of marginalized youth in our society, as well as discussion of social action that needs to be taken. Several of the researchers finished the project inspired to continue working for social change and with new ideas for how to do so by creating opportunities for certain groups in society to learn from each other. Thus, the researchers' own reflections on this process were as meaningful as the literal results of the program evaluation that this study produced. All researchers believed it was a very effective service learning experience.

\section{Limitations, Future Directions, and Conclusion}

While the current study provided valuable information for further program development, it is important to note some of the potential limitations. Perhaps most significantly, it was not clear which outcomes were attributable to which aspects of the programming, therefore a major recommendation to the program developers by the researchers was to clarify program goals and to more highly standardize the curriculum in accordance with these goals. Only then would specific outcomes be measurable through traditional summative evaluation. Secondly, although we met the minimal CQR methodology recommendation of eight participants (Hill et al., 2005), three were survivors and five were youth participants. We would have liked to have more than two focus groups and three interviews, to better describe a range of experiences. Unfortunately, we were unable to recruit further participants. Thirdly, some of the participants, particularly youth, may have felt it necessary to respond to researcher interviewers with positive answers about programming, particularly since researchers were asking questions specific to the impact or change caused by the program. The interviewers attempted to account for the possibility of participants responding in socially desirable ways by framing the focus groups as being about any reactions youth had, and several youth did share negative reactions to programming. Nevertheless, there may have still been a desire to respond positively. The specific nature of the questions may also have caused them to give responses that they would not have otherwise given. Finally, while we were able to see many themes of social justice running through the responses of the participants, asking more explicitly about this would be a valuable future direction. Future programs such as this may also want to formalize researcher reflections on the experience through journaling or other methods. 
A final reflection on this project concerns the difficulties of formally evaluating community-based programs in the "real-world," particularly those with ties to diversity awareness such as this one (Paluck, 2006). Like the MTC program, many social justice focused, community-based programs weren't developed with the thorough methodological approach that researchers use when developing "gold standard" reliable and measurable interventions. While our findings suggest that this program did have a positive impact on youth's development and highlight many crucial considerations in such programming, it is still unclear what specific psychological and social outcomes the MTC program facilitates. This "kitchen sink problem" (Paluck) is quite common in programs that are created by community entities to address immediate societal issues and needs (Blechman, 1992). Some recommendations in this area have included matching community programs and having one of the programs be on a waitlist (see Paluck, 2006, for a full description of an evaluation of a school diversity program managed in this way). However, given the community-based nature of the programming, it may be rather difficult to employ such methods of evaluation.

Given that many community-based programs weren't developed with empirically measurable outcomes in mind, researchers may find themselves in an ethical dilemma as they choose whether or not to conduct a community-based program evaluation that may not lead to the findings of more tightly controlled studies. Indeed, others have documented the socio-political-structural challenges of maintaining a research career in a competitive academic environment that places value on quickly producing empirical research. However, to echo the stance of social justice scholars (e.g., Lykes, Hershberg, \& Brabeck, 2011; Vera \& Speight, 2003), it is the position of the authors in this study that these research endeavors are valuable and can contribute to the scientific community nonetheless, while also contributing to the greater social good. This perspective augments the views of other scholars (e.g., Massey \& Barreras, 2013) who have argued for researchers to pay more attention to impact validity, defined as the potential impact a study may have on creating social change, when embarking on a research project, rather than focusing on traditional methodological rigor alone. As counselors and psychologists who strive to work through a social justice lens, evaluating the impact validity of a given research project seems imperative.

\section{Author Contact Information}

Correspondence regarding this article should be directed to: Melissa Morgan-Consoli at 2141 Education Building, University of California Santa Barbara, Santa Barbara, CA. 93006

Email:mmorgan@education.ucsb.edu

Melissa L. Morgan-Consoli, Ph.D. is an Associate Professor in the Counseling, Clinical and School Psychology department at the University of California, Santa Barbara. Her research interests lie in the areas of resilience, thriving, social justice and immigration, with an emphasis on Latino/a populations.

Brian Stevenson, Ph. D. is a Counseling Psychologist at the Edith Nourse Rogers Memorial Veteran's Hospital. His clinical and research interests include: vocational rehabilitation of veterans who are homeless, dual diagnosis, social justice engagement among psychologists, power and privilege in clinical settings, masculinity and mental health, and recovery-oriented models of care.

Erika Noriega-Pigg, Ph.D. is completing her Post-Doctoral Residency in Clinical Psychology at Kaiser Permanente Santa Rosa. Her research and clinical interests lie in the areas of Latinx Mental Health, Multicultural Psychology, social justice, and advocacy. 
Wendy Morrison received her Ph.D. in Clinical Psychology from the University of California, Santa Barbara. Her research and clinical interests include college student mental health, early detection and intervention, psychological assessment, mindfulness, Latino/a/x populations, and social justice issues.

Kelley P. Hershman, LMHC, PLLC is a Licensed Psychotherapist, Clinical Supervisor and Co-founder of The Soho Center for Psychotherapy and Clinical Learning in New York City. Her research interests include examining race, gender and status as they relate to power dynamics, authority and leadership in group and organizational culture.

Carlos Roman is an Aide for the Special Education Department at Jordan Middle School in Palo Alto, CA. His research interests lie in the areas of brain reward circuitry and special education.

\section{References}

Albee, G. W. (2000). Commentary on prevention and counseling psychology. The Counseling Psychologist, 28(6), 845-853. doi: 10.1177/0011000000286006

Ahrens, K., DuBois, D. L., Lozano, P., \& Richardson, L. P. (2011). Naturally acquired mentoring relationships and young adult outcomes among adolescents with learning disabilities. Learning Disabilities Research \& Practice, 25(4), 207-216. doi:10.1111/j.1540-5826.2010.00318

Allen, J., Kuperminc, G., Philiber, S., \& Herre, K. (1994). Programmatic prevention of adolescent problem behaviors: The role of autonomy, relatedness, and volunteer service in the Teen Outreach Program. American Journal of Community Psychology, 22, 617-638. doi:10.1007/BF02506896

Antonovsky, A., Maoz, B., Dowty, N., \& Wijsenbeek, H. (1971). Twenty-five years later: A Limited study of the sequelae of the concentration camp experience. Social Psychiatry, 6, 186-193.

doi:10.1007/ BF00578367

Beiser M., \& Johnson, P.J. (1994) A ten-year study of Southeast Asian Refugees in Canada. Report to Canada Health and Welfare NHRDP. Grant No. 6606-4918-64/2.

Blechman, E. (1992). Mentors for high-risk minority youth: From effective communication to bicultural competence. Journal of Clinical Child Psychology, 21, 160-169. doi:10.1207/s15374424jccp2102_8

Buhrmester, D. (1990). Intimacy of friendship, interpersonal competence, and adjustment during preadolescence and adolescence. Child Development, 61, 1101-1011. doi:10.2307/1130878

Caldwell, J.C. \& Vera, L. (2010). Critical incidents in counseling psychology professionals' and trainees social justice orientation development. Training and Education in Professional Psychology, 4, 163-176. 
Catalano, R. F., Hawkins, J. D., Berglund, L., Pollard, J. A., \& Arthur, M. W. (2002). Prevention science and positive youth development: Competitive or cooperative frameworks? Journal of Adolescent Health, 31, 230-239. doi:10.1016/S1054-139x(02)00496-2

Cook, J. (2014). Using evaluation to effect social change: Looking through a community psychology lens. American Journal of Evaluation, 36, 107-117. doi:10.1177/1098214014558504

Chodoff, P. (1963). Late effects of the concentration camp syndrome. Archives of General Psychiatry, 8, 323-333. doi:10.1001/archpsyc.1963.01720100013002

Diversi, M. \& Mechum, C. (2005). Latino(a) students and Caucasian mentors in a rural, after-school program: Towards empowering adult-youth relationships. Journal of Community Psychology, 33, 31-40. doi:10.1002/jcop.20034

DuBois, D. L., Holloway, B.E., Valentice, J.C., \& Cooper, H. (2002). Effectiveness of mentoring programs for youth: A meta-analytic review. American Journal of Community Psychology, 30(2), 157-197.

Eaton, L. G., Doherty, K. L., \& Widrick, R. M. (2007). A review of research and methods used to establish art therapy as an effective treatment method for traumatized children. The Arts in Psychotherapy, 34(3), 256-262. doi:10.1016/j.aip.2007.03.001

Elledge, L. C., Cavell, T. A., Ogle, N. T., \& Newgent, R. A. (2010). School-based mentoring as selective prevention for bullied children: A preliminary test. The Journal of Primary Prevention, 31(3), 171-187. doi:10.1007/s10935-010-0215-7

Fassinger, R., \& Morrow, S. L. (2013). Toward best practices in quantitative, qualitative, and mixedmethod research: A Social justice perspective. Journal for Social Action in Counseling and Psychology, 5, 69-83.

Grodin, M. A. (2011). Caring for aging Holocaust survivors and subsequent generations. American Imago, 68(3), 543-559. doi: 10.1353/aim.2011.0034

Gutman, L. M., \& Schoon, I. (2015). Preventive interventions for children and adolescents: A review of meta-analytic evidence. European Psychologist, 20(4), 231-241. doi:10.1027/10169040/a000232

Hass, A. (1995). Survivor guilt in Holocaust survivors and their children. A global perspective on working with holocaust survivors and the second generation. Jerusalem: Amcha/JDC Brookdale.

Herrera, C., Grossman, J. B., Kauth, T. J., Feldman, A. F., McMaken, J., \& Jucovy, L. Z. (2007). Making a difference in schools: The Big Brothers Big Sisters school-based mentoring impact study. Philadelphia, PA: Public/Private Ventures.

Higgins, G. (1994). Resilient adults: Overcoming a cruel past. San Francisco: Jossey-Bass. 
Hill, C. E., Thompson, B. J., Hess, S. A., Know, S., Nutt Williams, E., \& Ladany, N. (2005). Consensual qualitative research: An update. Journal of Counseling Psychology, 52, 196-205. doi:10.1037/0022-0167.52.2.196

Hill, C. E., Thompson, B. J., \& Nutt Williams, E. (1997). A guide to conducting consensual qualitative research. The Counseling Psychologist, 25, 517-572. doi:10.1177/0011000097254001

Holloway, I., \& Todres, L. (2003). The status of method: Flexibility, consistency and coherence. Qualitative Research, 3, 345-357. doi:10.1177/1468794103033004

lecovich, E. \& Carmel, S. (2010). Health and functional status and utilization of health care services among holocaust survivors and their counterparts in Israel. Archives of Gerontology and Geriatrics, 51 (3), 304-308. doi:10.1016.2010.01.005

Keller, T.E. \& Pryce, J.M. (2010). Mutual but unequal T Mentoring as a hybrid of familiar relationship roles. New Directions in Youth Development, 126, 33-50.

Kestenberg, J. (1998). Adult survivors, child survivors, and children of survivors. In J.S. Kestendberg \& C. Kahn (Eds.), Children surviving persecution: An international study of trauma and healing (pp. 56-65). Westport, CT: Praeger.

Kline-Parker, F. (1988). Dominant attitudes of adult children of Holocaust survivors toward their parents. In J.P. Wilson \& B. Kahana, (Eds.) Human adaptation to extreme stress. New York: Plenum, 193217.

Knightbridge, S. M., King, R., \& Rolfe, T. J. (2006). Using participatory action research in a communitybased initiative addressing complex mental health needs. Australian and New Zealand Journal of Psychiatry, 40, 325-332. doi: 10.1111/j.1440-1614.2006.01798.x

Lerner, R.M., Fisher, C.B., \& Weinberg, RA. (2000). Toward a science for and of the people: Promoting civil society through the application of developmental science. Child Development, 71(1), 11-20. doi:10.1111/1467-8624.00113

Lykes, M. B., Hershberg, R. M., \& Brabeck, K. M. (2011). Methodological challenges in participatory action research with undocumented Central American migrants. Journal for Social Action in Counseling and Psychology, 3, 22-35.

Lyons, H. Z., Bike, D. H., Ojeda, L., Johnson, A., Rosales, R., \& Flores, L. Y. (2013). Qualitative research as social justice practice with culturally diverse populations. Journal for Social Action in Counseling and Psychology, 5, 10-25.

Mark, M. M., \& Henry, G. T. (2004). The mechanisms and outcomes of evaluation influence. Evaluation: The International Journal of Theory, Research and Practice, 10, 35-57. doi: $10.1177 / 1356389004042326$

Massey, S. G., \& Barreras, R. E. (2013). Introducing impact validity. Journal of Social Issues, 69, 615-632. doi:10.1111/josi.12032 
Niederland, W. G. (1968). The problem of the survivor: The psychiatric evaluations of emotional problems in survivors of Nazi persecution. In H. Krystal (Ed.), Massive psychic trauma (pp. 8-22). New York, NY: International University Press.

Oberle, E. Schonert-Reichl, K. A., \& Zumbo, B. D. (2011). Life satisfaction in early adolescence: Personal, neighborhood, school, family, and peer influences. Journal of Youth Adolescence, 40, 889-901. doi:10.1007/s10964-010-9599-1

Paluck, E. L. (2006). Diversity training and intergroup contact: A call to action research. Journal of Social Issues, 62(3), 577-595. doi: 10.1111/j.1540-4560.2006.00474.x

Ponterotto, J.G., Matthew, J.T., \& Raughley, B. (2013). The value of mixed-methods designs to social justice research in counseling and psychology. Journal for Social Action in Counseling and Psychology, 5, 42-68.

Prilleltensky, I. (1989). Psychology and the status quo. American Psychologist, 44, 795-802.

Rhodes, J. E., Reddy, R., \& Grossman, J. B. (2005). The protective of influence of mentoring on adolescents' substance use: Direct and indirect pathways. Applied Developmental Science, 9, 3147. doi:10.1207/s1532480xads0901_4

Rogers, P. (2002). Program theory: Not whether programs work but how they work. Evaluation in Education and Human Services, 49, 209- 232. doi:10.1007/0-306-47559-6_13

Safford, F. (1995) Aging stressors for Holocaust survivors and their families. Journal of Gerontological Social Work 24(1/2): 131-53. doi:10.1300/J083V24N01_10

Scales, P. C. (2003). Other people's kids: Social expectations and American adults' involvement with children and adolescents. New York: Kluwer Academic/Plenum.

Scales, P. C., Benson, P. L., \& Mannes, M. (2006). The contribution to adolescent well-being made by non-family adults: An examination of developmental assets as contexts and processes. Journal of Community Psychology, 34, 401-413. doi:10.1002/jcop.20106

Spencer, R. (2007). "It's not what I expected": A qualitative study of youth mentoring relationship failures. Journal of Adolescent Research, 22, 331-354.

Stanford Center on Longevity (2011). Demographic profile: Santa Barbara County. Retrieved from: https://www.library.ca.gov/lds/demographicprofiles/docsreference/Santa\%20Barbara\%20County\%20DP2010.pdf

Stuckey, H. L., \& Nobel, J. (2010). The connection between art, healing, and public health: A review of current literature. American Journal of Public Health, 100(2), 254-263.

doi:10.2105/AJPH.2008.156497 
Taylor, A. S., \& Dryfoos, J. G. (1998). Creating a safe passage: Elder mentors and vulnerable youth. Generations, 22(4), 43.

Theokas, C., Almerigi, J. B., Lerner, R. M., Dowling, E. M., Benson, P. L., Scales, P. C., et al. (2005). Conceptualizing and modeling developmental and ecological asset components of thriving in early adolescence. Journal of Early Adolescence, 25, 113-143. doi:10.1177/0272431604272460

Thomas, V. G., \& Madison, A. (2010). Integration of social justice into the teaching of evaluation. American Journal of Evaluation, 31, 570-583. doi:10.1177/1098214010368426

Tolan, P.H., Henry, D.B., Schoeny, M.S., Lovegrove, P., \& Nichols, E. (2014). Mentoring programs to affect delinquency and associated outcomes of youth at risk: A comprehensive meta-analytic review. Journal of Experimental Criminology, 10(2), 179-206.

Toporek, R. \& Worthington, R. (2014). Integrating service learning and difficult dialogues pedagogy to advance social justice training. The Counseling Psychologist, 42, 919- 945.

Vera, E. M., \& Speight, S. L. (2003). Multicultural competence, social justice, and counseling psychology: Expanding our roles. The Counseling Psychologist, 31, 253-272. doi:10.1177/0011000002250634

Werner, E. E., \& Smith, R. S. (1992). Overcoming the odds: High risk children from birth to adulthood. Ithaca, NY: Cornell University Paperbacks.

Wolfson, E.R. (2011). Holocaust survivors and gang members: An encounter transforming participants' attitudes towards vengeance and forgiveness. Retrieved from: www.inter-disciplinary.net/wpcontent/uploads/2011/06/erwolfsonepaper.pdf

Worthington, R. L., \& Arévalo Avalos, M. R. (2017). Difficult dialogues in counselor training and higher education. In C. M. Alexander, J. M. Casas, L. A. Suzuki, \& M. Jackson (Eds.), Handbook of multicultural counseling (4th ed.) (pp. 360-372). Thousand Oaks, CA: Sage.

\section{Appendix 1. Semi-Structured Interview Questions- Mis Tres Caras Youth Focus Groups}

1. Please tell us about your experience with the Mis Tres Caras Program.

a. What activities did you find most helpful? Why?

b. What activities did you feel were not helpful to you or your situation? Why?

2. How have you changed since completing the program?

a. (prompt) Did you feel different about yourself after finishing the program? How?

b. (prompt) What changes do you think other people have noticed about you since the program?

c. (prompt) After finishing this program, what did you learn about yourself?

3. Can you describe your relationship with the survivors?

a. What was it like to have a connection with a survivor?

b. Did the survivors help you change? If so, how?

4. What challenges have you had since finishing the program?

a. How did this experience help you with these challenges? 


\section{Appendix 2. Semi-Structured Interview Questions- Mis Tres Caras Mentors}

1. How did you hear about the Mis Tres Caras (MTC) program?

2. In what capacity have you been involved in MTC?

3. Please tell us about your experience with the MTC Program.

a. (prompt if not covered) What do you see as the goals of the MTC program?

b. (prompt) Do you think this program is effective? Does it work?

c. (prompt) What do you think makes the program work?

d. (prompt) What activities in the program do you think are most helpful? Why?

e. (prompt) What activities do you feel are the most challenging? Why?

4. Can you describe your relationship with the participants? (prompt) What was it like to have a connection to community youth?

5. Many have said that the program impacts the youth significantly, do you agree? If so, what do you think causes this impact?

6. Do you feel that you have changed since volunteering for the program? If so, how?

a. (prompt) What does it mean for you personally to be involved with the MTC program?

b. (prompt) What are the benefits?

c. (prompt) What are the challenges? How do you deal with those challenges? 